Supporting Information for

\title{
Molecular Engineering of Polymeric Hole-Transporting Material for Efficient and Stable Perovskite Solar Cells
}

Yan Lia ${ }^{\mathrm{a}, \mathrm{b}}$, Shichun Duan ${ }^{\mathrm{b}}$, Luozheng Zhang ${ }^{\mathrm{b}, \mathrm{c}}$, Yong Zhang ${ }^{\mathrm{b}}$, Zikang Tang ${ }^{\mathrm{a}, *}$, Baomin Xu ${ }^{\mathrm{b}, *}$

anstitute of Applied Physics and Materials Engineering, University of Macau, Macau 999078, China.

bDepartment of Materials Science and Engineering and Shenzhen Engineering Research and Development Center for Flexible Solar Cells, Southern University of Science and Technology, Shenzhen 518055, China

cAcademy for Advanced Interdisciplinary Studies, Southern University of Science and Technology, Shenzhen 518055, China

*Corresponding authors, Email: zktang@um.edu.mo (Zikang Tang), xubm@sustech.edu.cn (Baomin Xu)

Keywords: perovskite solar cells; dopant-free; hole-transporting materials; thiophene; $\pi$ conjugation 
1. Synthesis of the polymer

Materials: 2,5'-Bis[(5-trimethylstannyl)-2-thienyl]thiophene was purchased from SunaTech Inc., and the other reagents and solvents were from Aladdin, J\&K Scientific Ltd., or SigmaAldrich.
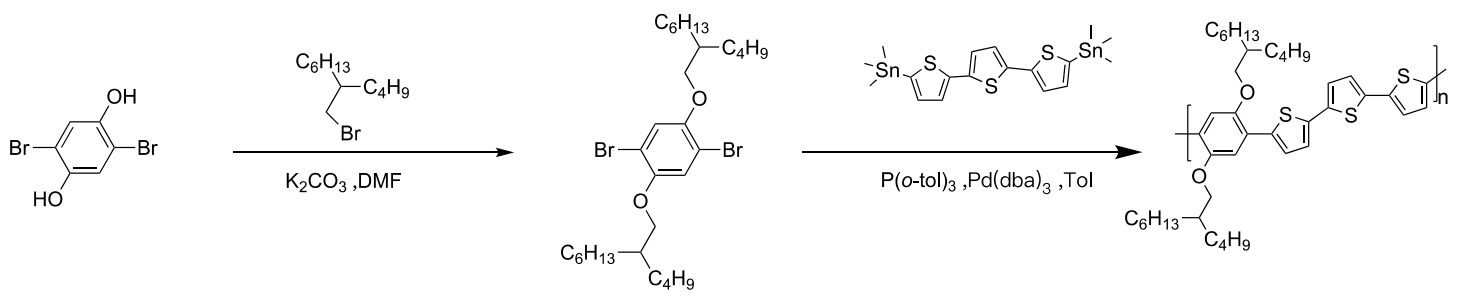

Scheme S1. Synthetic route to polymer TTB

1,4-dibromo-2,5-bis((2-butyloctyl)oxy)benzene: Into a pre-dried $250 \mathrm{~mL}$ flask were charged with 2,5-dibromobenzene-1,4-diol $(2.0 \mathrm{~g})$ and $\mathrm{K}_{2} \mathrm{CO}_{3}(4.13 \mathrm{~g})$. The flask was successively evacuated and refilled with argon for 3 cycles. Then DMF $(37 \mathrm{~mL})$ was added, and 5(bromomethyl) undecane (3.6 g) was introduced in one portion with a syringe after the completely dissolution of the mixture. The flask was subsequently stirred at $100{ }^{\circ} \mathrm{C}$ for 20 hours. After cooling to room temperature, the reaction mixture was concentrated with a rotary evaporator and the organic layer was extracted with ethyl acetate and rinsed with water. Further purification was performed by column chromatography with hexane as the eluent to yield the final product.2.3g, yield:62.6\%. ${ }^{1} \mathrm{H}$ NMR $\left(400 \mathrm{MHz}, \mathrm{CDCl}_{3}, \delta\right): 7.07(\mathrm{~s}, 2 \mathrm{H}), 3.83(\mathrm{~d}, 4 \mathrm{H}), 1.75(\mathrm{~m}$, 2H), 1.58-1.38 (m, 16H), 1.36-1.30 (m, 16H), 0.95-0.90 (m, 12H). ${ }^{13} \mathrm{C}$ NMR (400MHz, $\mathrm{CDCl}_{3}$,

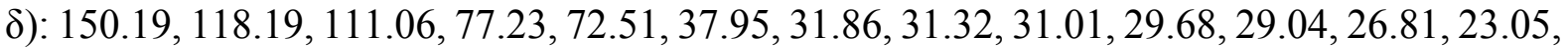
$22.70,14.14,14.11$.

Polymer TTB: Into a pre-dried $25 \mathrm{~mL}$ flask were charged with 1,4-dibromo-2,5-bis((2butyloctyl)oxy)benzene $(183.8 \mathrm{mg})$ 、 2,5'-Bis[(5-trimethylstannyl)-2-thienyl]thiophene 
$(174.5 \mathrm{mg})$ and $\mathrm{P}(o-\text { tol })_{3}(22.2 \mathrm{mg})$. The flask was successively evacuated and refilled with argon for 3 cycles. Then toluene $(15 \mathrm{~mL})$ was added, and the mixture was purged with argon for $20 \mathrm{~min}$. After the addition of $\operatorname{Pd}(\mathrm{dba})_{3}(8.4 \mathrm{mg})$ purging for another $15 \mathrm{~min}$ was conducted. The reaction mixture was stirred at $120^{\circ} \mathrm{C}$ for 48 hours. After cooling to room temperature, the crude product was collected by precipitating from acetone. The solid was rinsed in a Soxhlet extractor with hexane, methanol, acetone, and chloroform successively. The solution in chloroform was concentrated and then precipitated in acetone. The polymer was obtained after drying at reduced pressure. $180.5 \mathrm{mg}$, yield: 63.6\%. $\mathrm{M}_{\mathrm{n}}$ : 25036; PDI: 1.69.

\section{General characterization}

${ }^{1} \mathrm{H} \mathrm{NMR}$ spectrum in $\mathrm{CDCl}_{3}$ was measured on a Bruker ADCANCE III 400M magnet equipped with BBFO SmartProbe. The absorption spectrum was measured with a PerkinElmer Lambda $650 \mathrm{~S} \mathrm{UV/VIS} \mathrm{spectrometer.} \mathrm{Gel} \mathrm{permeation} \mathrm{chromatography} \mathrm{(GPC)} \mathrm{was} \mathrm{performed} \mathrm{on}$ Polymer Laboratories GPC-PL220 high-temperature GPC/SEC system at $150{ }^{\circ} \mathrm{C}$ using polystyrene as the standard and Tetrahydrofuran as the eluent. 


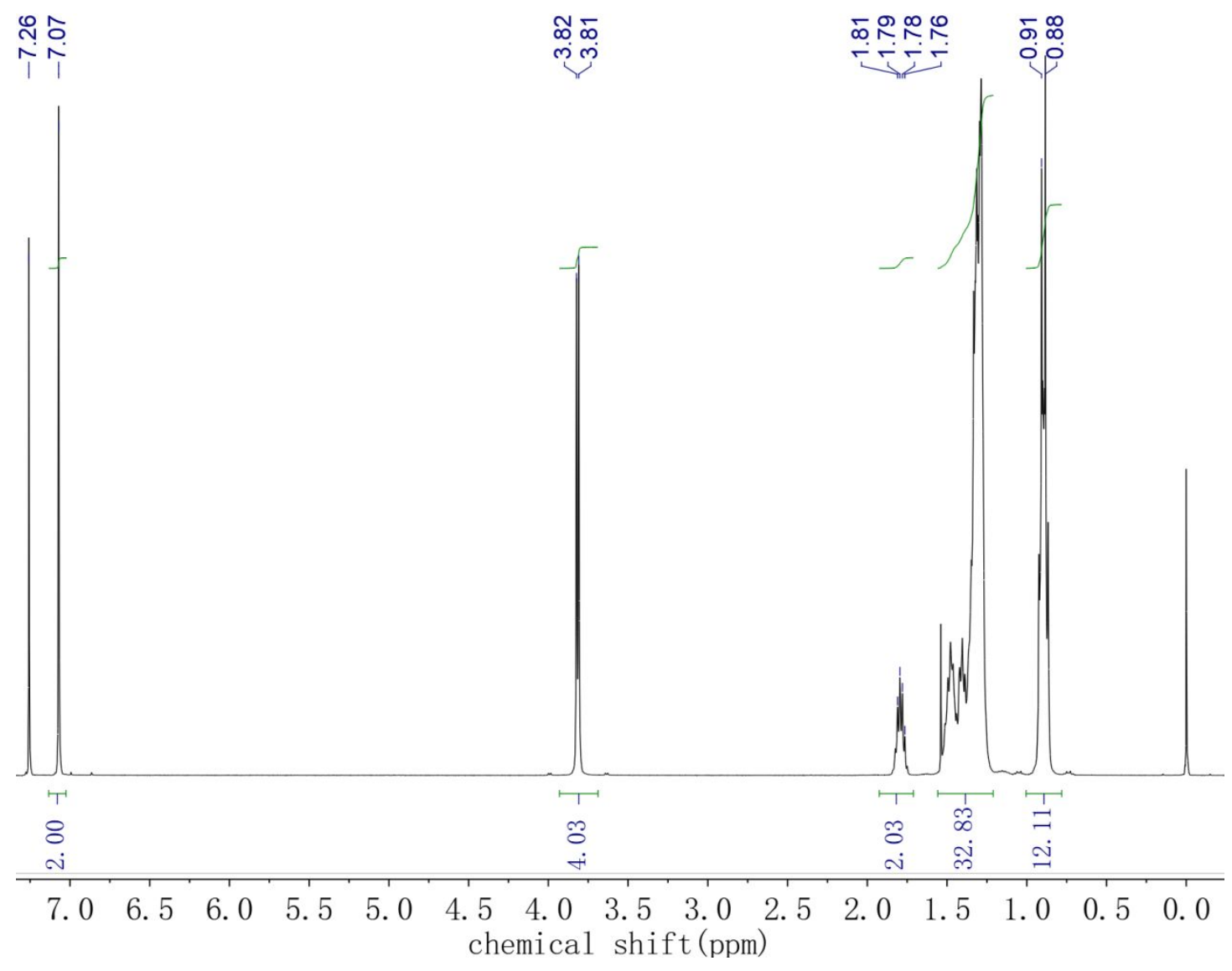

Figure S1. H NMR spectrum for 1,4-dibromo-2,5-bis((2- butyloctyl)oxy)benzene. 

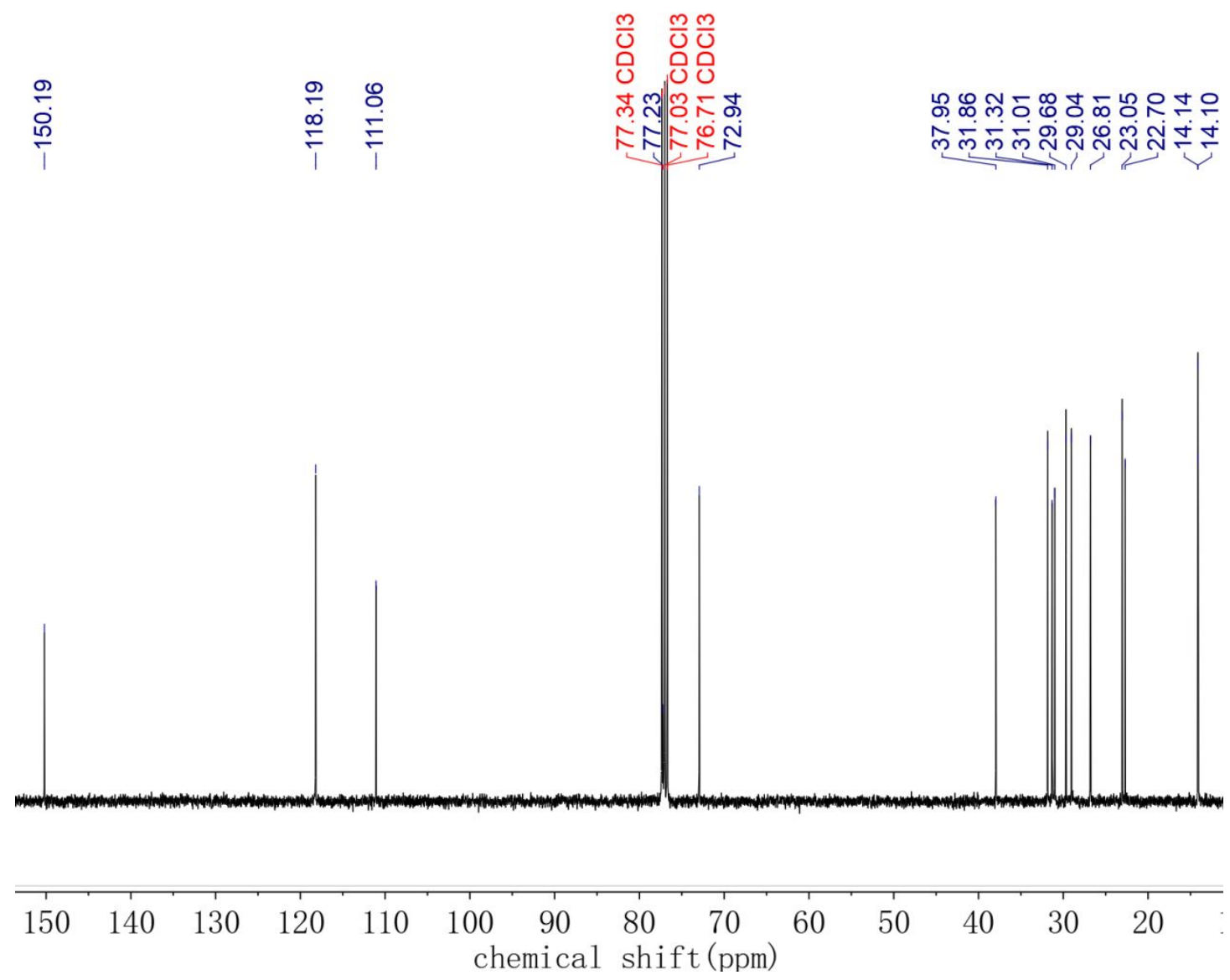

Figure S2. ${ }^{13} \mathrm{C}$ NMR spectrum for 1,4-dibromo-2,5-bis((2- butyloctyl)oxy)benzene.

MW Averages
Mp: 32781
$\mathrm{Mn}: 25036$
Mw:42352
Mz: 70604
$\mathrm{Mz}+1: 119055$
PD: 1.6916

\section{Distribution Plots}

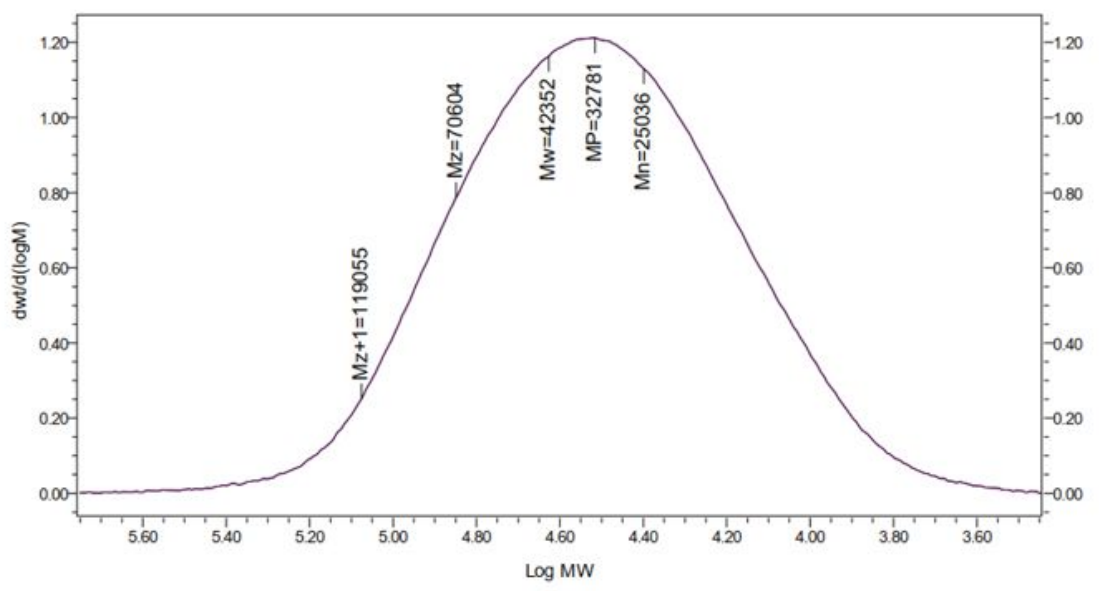

Figure S3. GPC result for TTB 

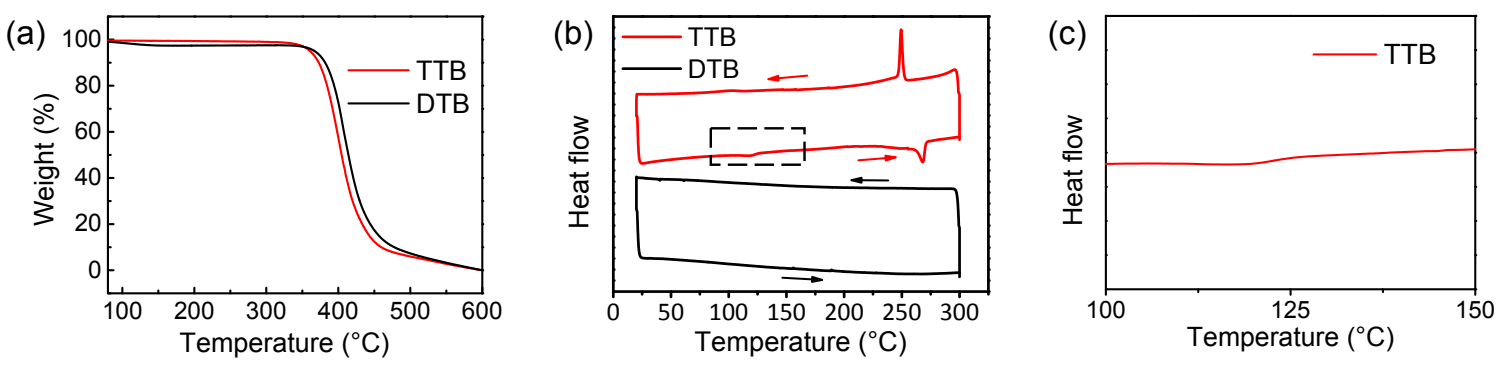

Figure S4. (a) Thermogravimetric analysis of TTB and DTB. (b) Differential scanning calorimetry of TTB and DTB. (c) Magnification of the rectangular area marked with dash line in Figure S4b.

(a)

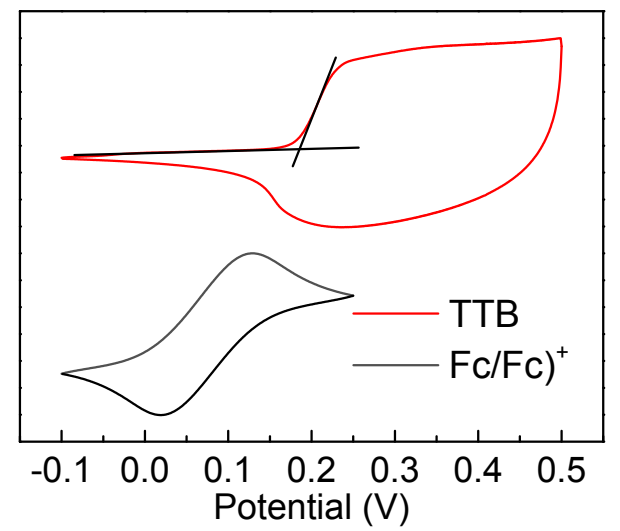

(b)

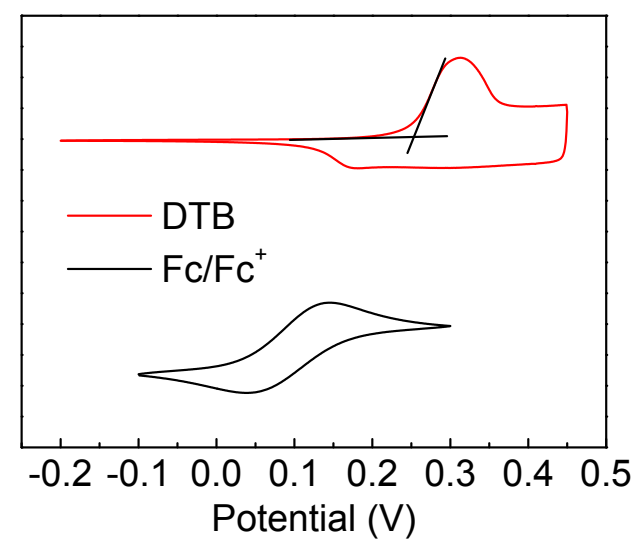

Figure S5. Cyclic Voltammetry curves for (a) TTB and $\mathrm{Fc} / \mathrm{Fc}^{+}$and (b) DTB and $\mathrm{Fc} / \mathrm{Fc}^{+}$. 
(a)

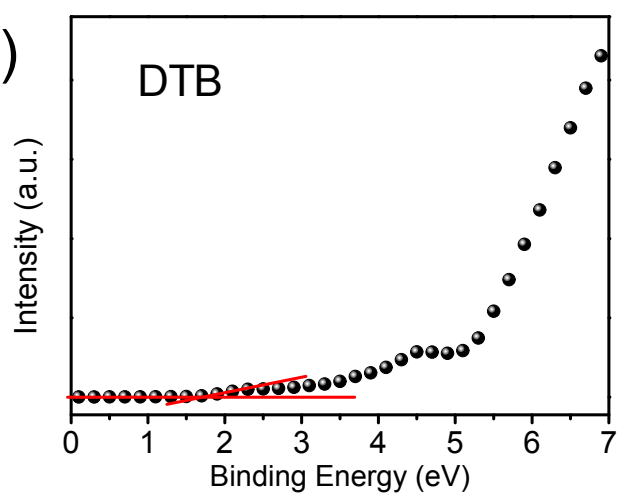

(c)

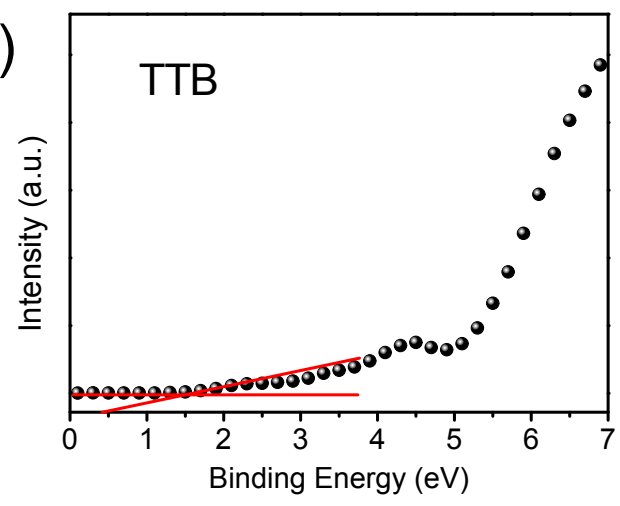

(b)

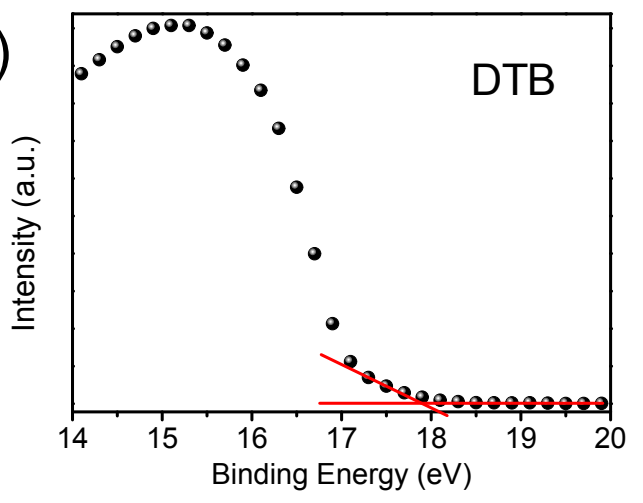

(d)

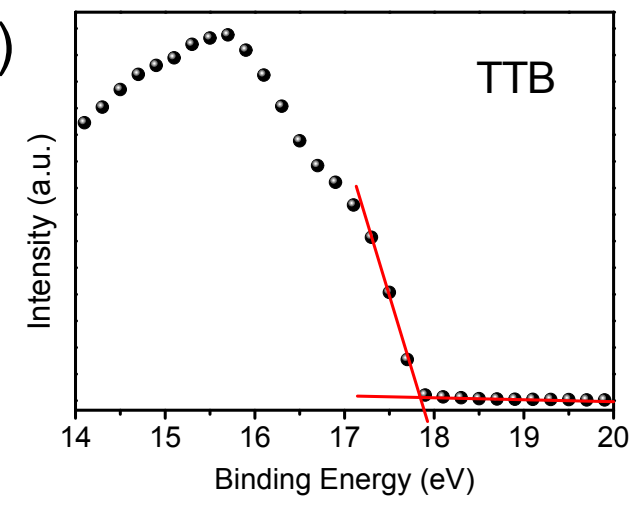

Figure S6. Ultraviolet Photoelectron Spectroscopy (UPS) spectra of (a) secondary edge region and (b) HOMO region of DTB, (c) secondary edge region and (d) HOMO region of TTB.

(a)

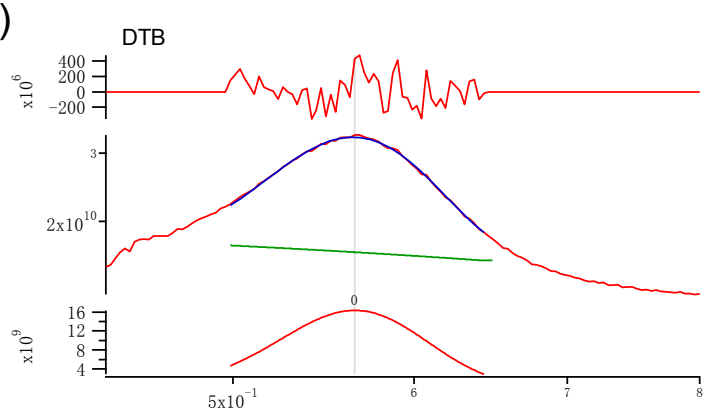

(b)

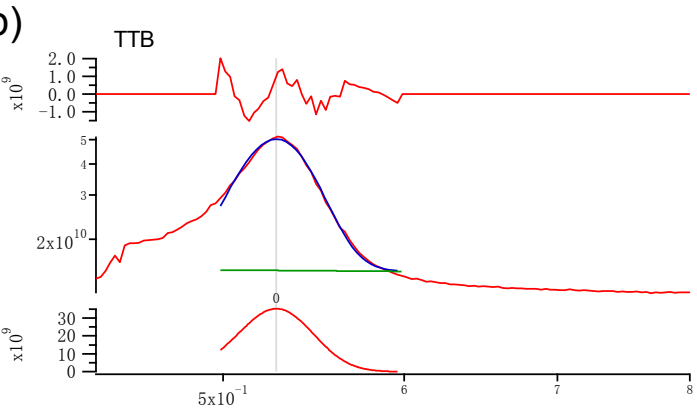

Figure S7. The fitting results of in plane GIWAXS profiles at low-q vector for (a) DTB and (b) TTB films. 
(a)

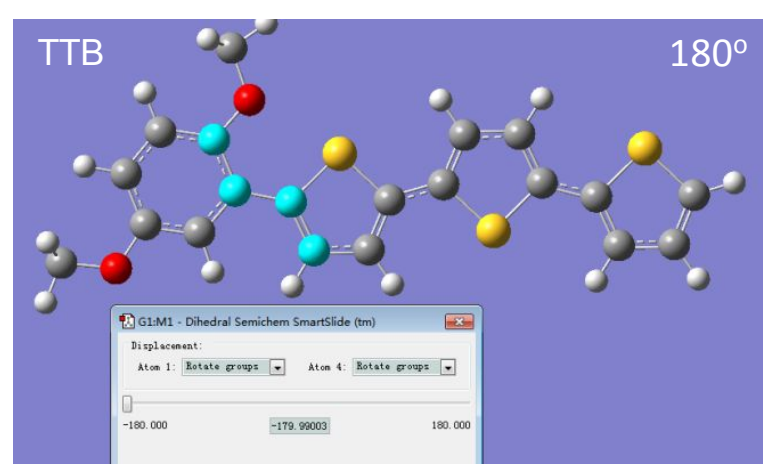

(b)

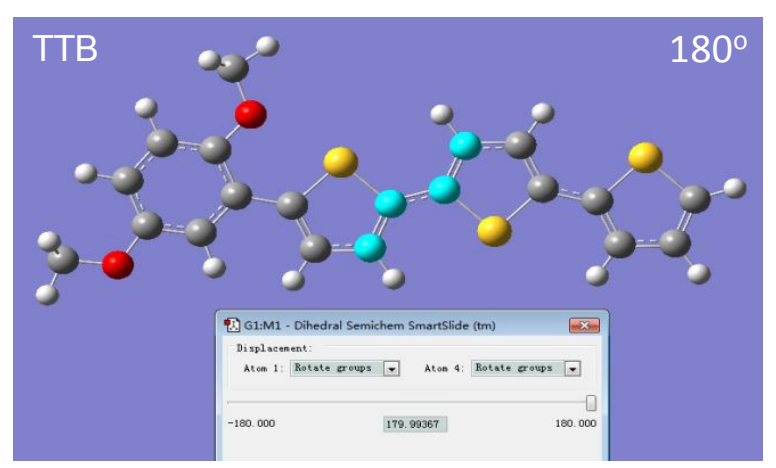

(c)

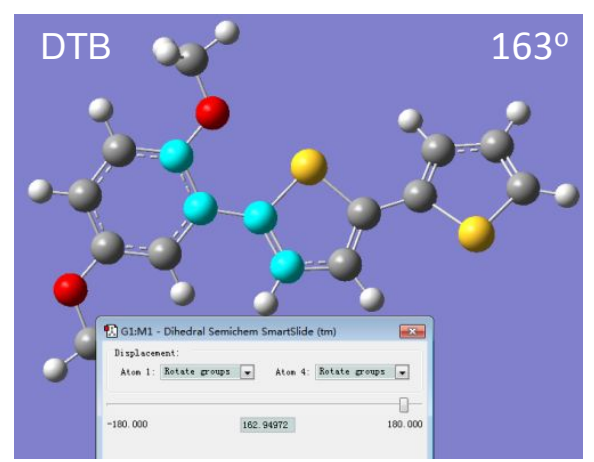

(d)

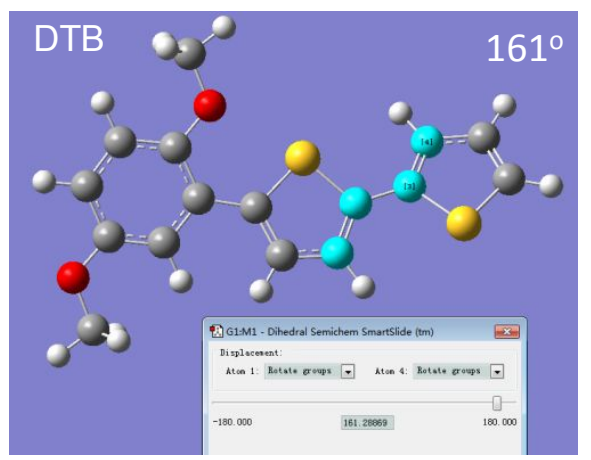

Figure S8. Calculations of dihedral angles between a) benzene ring and thiophene ring and b) thiophene ring and thiophene ring in TTB. The calculated dihedral angles between c) benzene ring and thiophene ring and d) thiophene ring and thiophene ring in DTB.
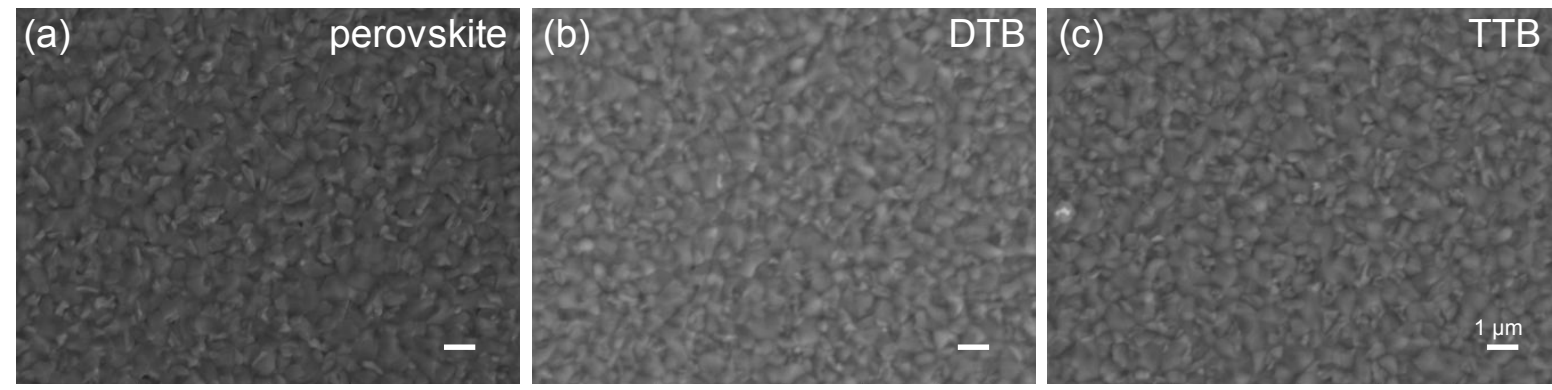

Figure S9. Top-view SEM images of perovskite, perovskite/DTB and perovskite/TTB. 


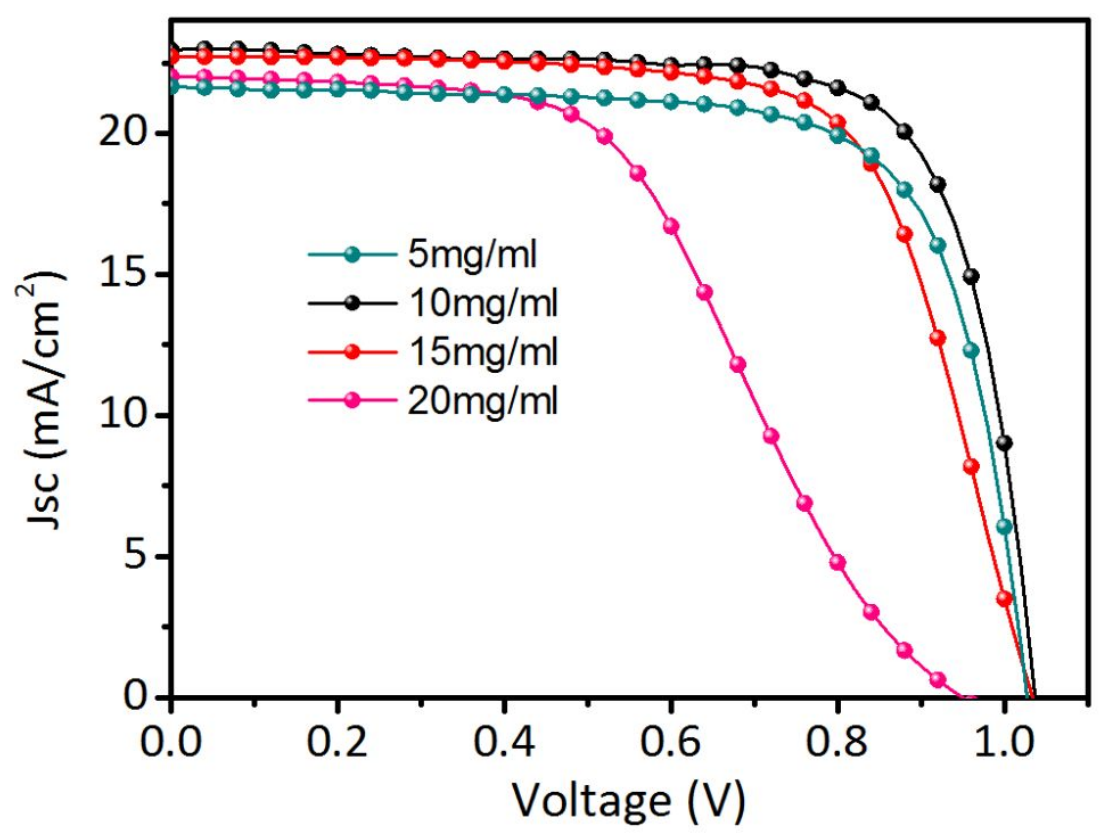

Figure S10. J-V curves of solar cells with different concentrations of TTB.

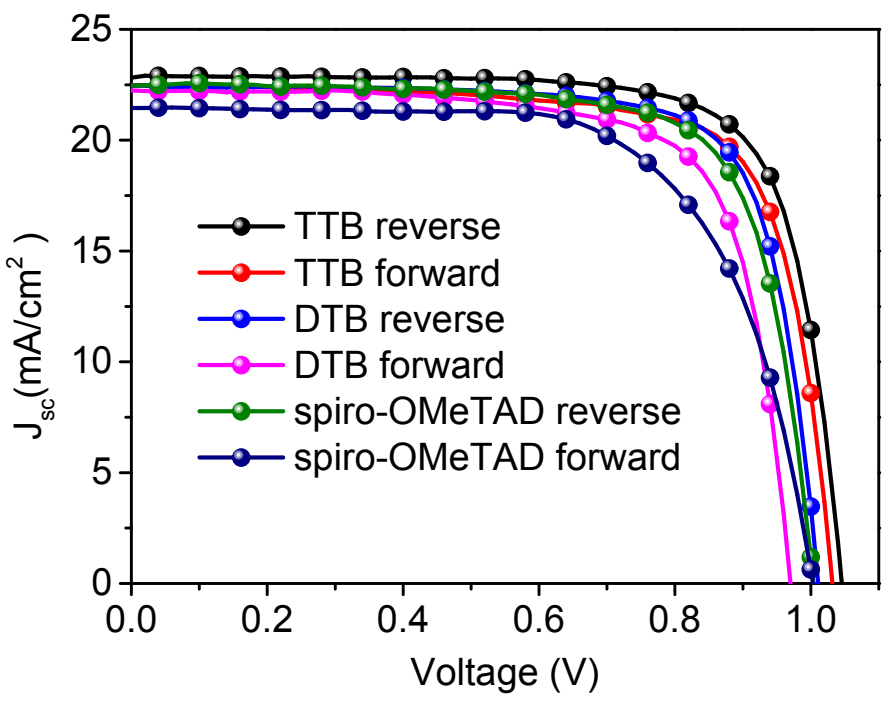

Figure S11. Reverse and forward scanned J-V curves of solar cells based on DTB and TTB HTM. 


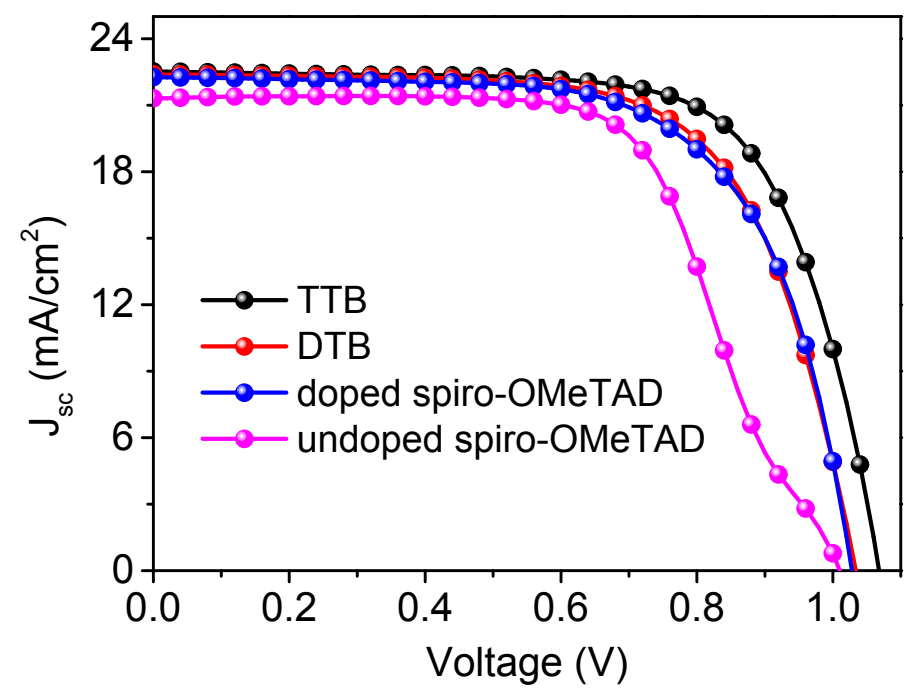

Figure S12. J-V curves of TTB, DTB, doped spiro-OMeTAD and undoped spiro-OMeTAD based devices. The cells were tested by using mask with area of $0.2 \mathrm{~cm}^{2}$.

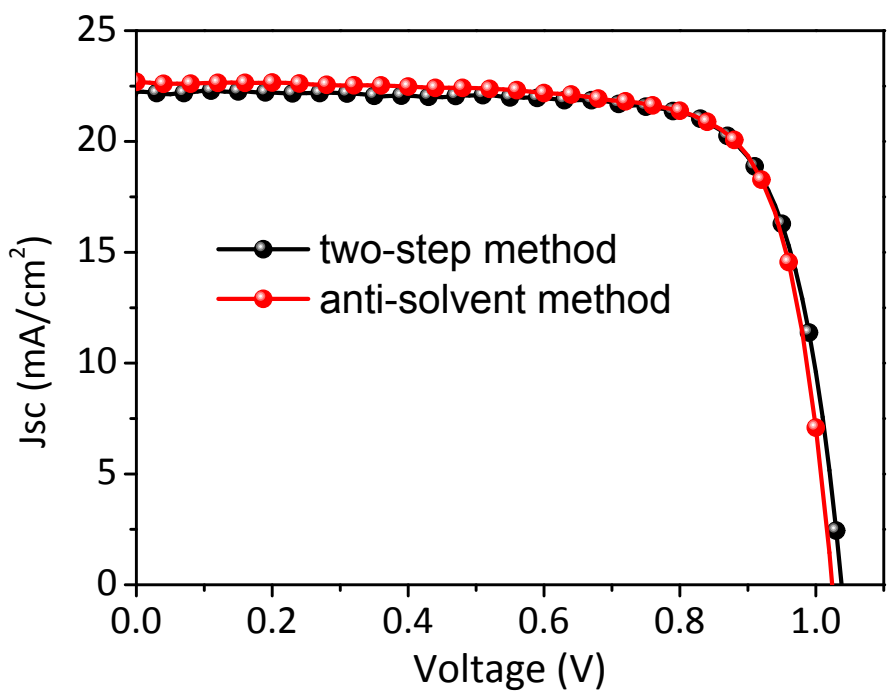

Figure S13. J-V curve obtained from two-step and anti-solvent fabrication methods. 
(a)

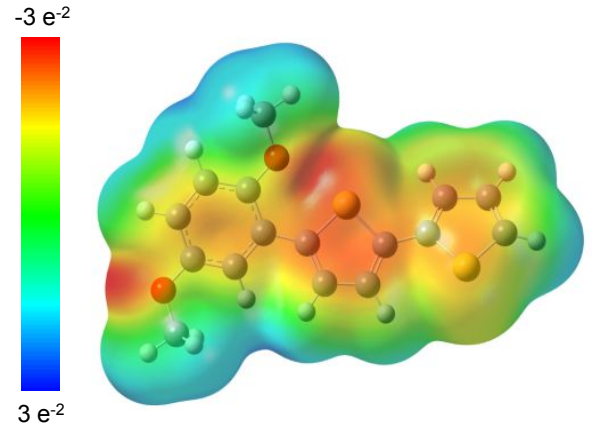

(b)

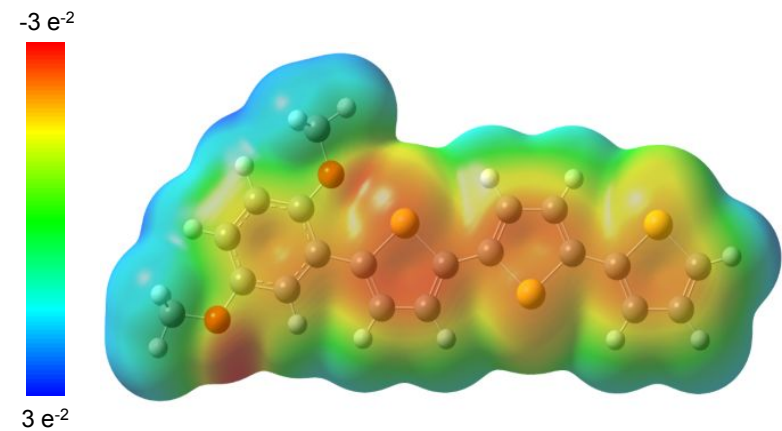

Figure S14. Electrostatic potential surface (EPS) of (a) DTB and (b) TTB calculated by DFT.

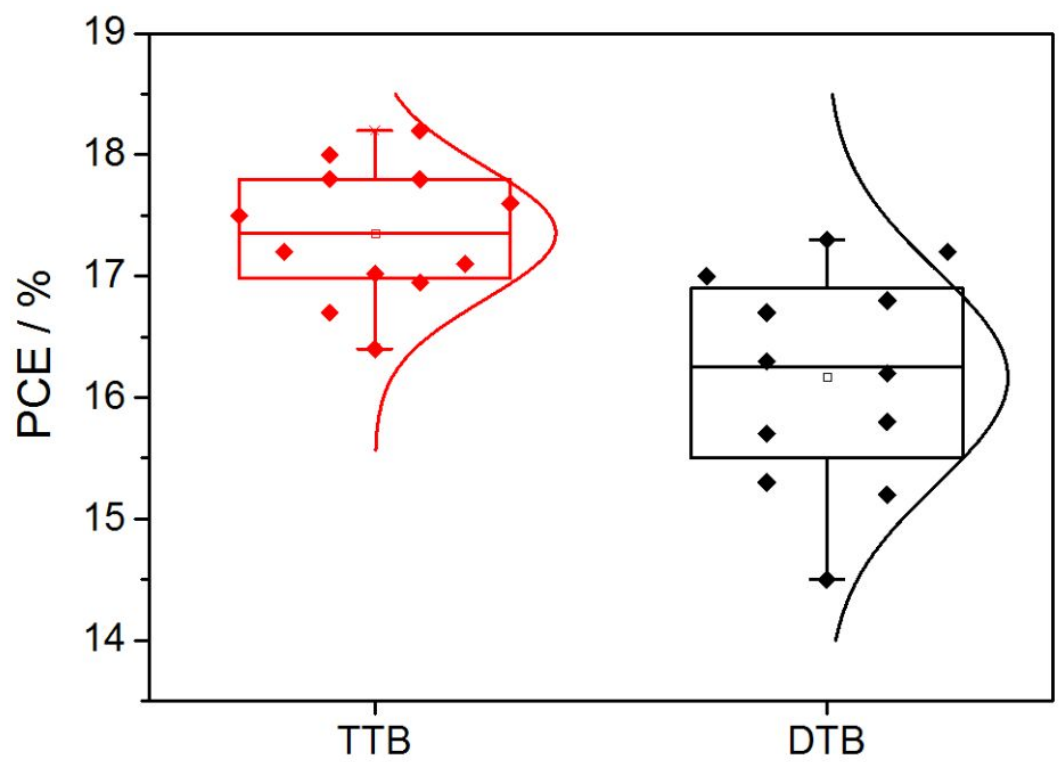

Figure S15. Distribution of PCE of different batches of devices based on TTB and DTB. 
(a)

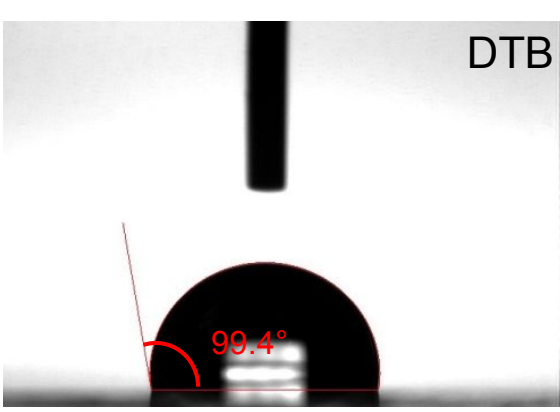

(b)

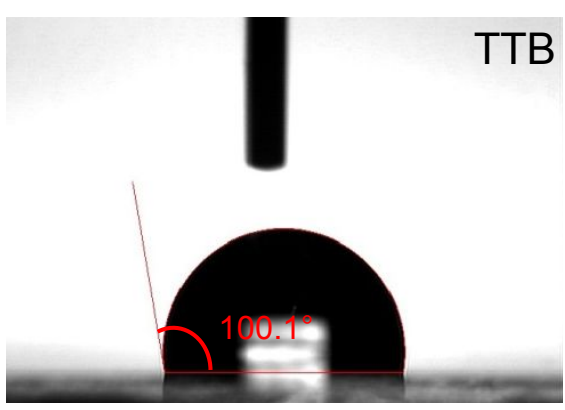

Figure S16. The contact angles of DTB and TTB. 
Table S1. Energy levels extracted from CV and UV-vis characterization.

\begin{tabular}{cccc}
\hline Polymer & $\begin{array}{c}\text { Optical bandgap } \\
{[\mathrm{eV}]}\end{array}$ & $\begin{array}{c}\text { HOMO level } \\
{[\mathrm{eV}]}\end{array}$ & $\begin{array}{c}\text { LUMO level } \\
{[\mathrm{eV}]}\end{array}$ \\
\hline TTB & 2.11 & -4.92 & -2.81 \\
DTB & 2.13 & -4.96 & -2.83 \\
\hline
\end{tabular}

Table S2. Hole mobility results extracted from SCLC fitting curve.

\begin{tabular}{ccc}
\hline Polymer & $\begin{array}{c}\text { Thickness } \\
{[\mathbf{n m}]}\end{array}$ & $\begin{array}{c}\text { Hole mobility } \\
{\left[\mathbf{c m}^{\mathbf{2}} \mathbf{V}^{-1} \mathbf{s}^{-1}\right]}\end{array}$ \\
\hline TTB & 150 & $6.5 \times 10^{-5}$ \\
DTB & 130 & $1.31 \times 10^{-5}$ \\
\hline
\end{tabular}

Table S3. Fitting results of GIWAXS profiles at low-q vector of in-plane direction.

\begin{tabular}{ccccc}
\hline \multirow{2}{*}{ Polymer } & $\begin{array}{c}\mathbf{q} \\
{\left[\AA^{-1}\right]}\end{array}$ & $\begin{array}{c}\text { d-spacing } \\
{[\AA]}\end{array}$ & $\begin{array}{c}\text { FWHM } \\
{\left[\AA^{-1}\right]}\end{array}$ & $\begin{array}{c}\text { CCL } \\
{[\mathbf{n m}]}\end{array}$ \\
\hline TTB & 0.53 & 11.9 & 0.049 & 11.4 \\
DTB & 0.57 & 11.0 & 0.098 & 5.7 \\
\hline
\end{tabular}

Table S4. Fitting results of normalized TRPL data.

\begin{tabular}{ccccc}
\hline Polymer & $\mathbf{A}_{\mathbf{1}}$ & $\boldsymbol{\tau}_{\mathbf{1}} / \mathbf{n s}$ & $\mathbf{A}_{\mathbf{2}}$ & $\boldsymbol{\tau}_{\mathbf{2}} / \mathbf{n s}$ \\
\hline TTB & 784.31 & 0.77 & 0.1 & 10.75 \\
DTB & 164.56 & 1.02 & 0.07 & 13.61 \\
\hline
\end{tabular}

Table S5. Photovoltaic parameters of PSCs with different concentrations of TTB.

\begin{tabular}{ccccc}
\hline $\begin{array}{c}\text { Concentration } \\
{[\mathbf{m g} / \mathbf{m L}]}\end{array}$ & $\begin{array}{c}\text { Voltage } \\
{[\mathbf{V}]}\end{array}$ & $\begin{array}{c}\text { Current density } \\
{\left[\mathbf{m A} \mathbf{\mathbf { c m } ^ { 2 }}\right]}\end{array}$ & $\begin{array}{c}\text { FF } \\
{[\%]}\end{array}$ & $\begin{array}{c}\text { PCE } \\
{[\%]}\end{array}$ \\
\hline 5 & 1.03 & 21.6 & 72.5 & 16.1 \\
10 & 1.04 & 23.0 & 74.7 & 17.8 \\
15 & 1.03 & 22.7 & 69.4 & 16.3 \\
20 & 0.93 & 22.2 & 53.0 & 11.0 \\
\hline
\end{tabular}

Table S6. Reverse and forward scanned photovoltaic parameters of solar cells based on DTB and TTB HTM.

\begin{tabular}{cccccc}
\hline \multirow{2}{*}{ HTM } & Scan direction & $\begin{array}{c}\text { Voltage } \\
{[\mathbf{V}]}\end{array}$ & $\begin{array}{c}\text { Current density } \\
{\left[\mathbf{m A} / \mathbf{c m}^{2}\right]}\end{array}$ & $\begin{array}{c}\text { FF } \\
{[\mathbf{\%}]}\end{array}$ & $\begin{array}{c}\text { PCE } \\
{[\%]}\end{array}$ \\
\hline \multirow{2}{*}{ TTB } & reverse & 1.04 & 22.8 & 76.4 & 18.2 \\
& forward & 1.03 & 22.5 & 74.9 & 17.4 \\
\multirow{2}{*}{ DTB } & reverse & 1.01 & 22.5 & 76.1 & 17.3 \\
& forward & 0.97 & 22.3 & 73.3 & 15.8 \\
Spiro- & reverse & 1.00 & 22.5 & 74.6 & 16.8 \\
OMeTAD & forward & 1.00 & 21.5 & 66.3 & 14.4 \\
\hline
\end{tabular}


Table S7. Photovoltaic parameters of TTB, DTB, doped spiro-OMeTAD and undopedOMeTAD devices tested with mask area of $0.2 \mathrm{~cm}^{2}$.

\begin{tabular}{ccccc}
\hline HTM & $\begin{array}{c}\text { Voltage } \\
{[\mathbf{V}]}\end{array}$ & $\begin{array}{c}\text { Current density } \\
{\left[\mathbf{m A} / \mathbf{c m}^{2}\right]}\end{array}$ & $\begin{array}{c}\text { FF } \\
{[\% \mathbf{o}]}\end{array}$ & $\begin{array}{c}\text { PCE } \\
{[\% \mathbf{o}]}\end{array}$ \\
TTB & 1.07 & 22.5 & 70.1 & 16.9 \\
DTB & 1.03 & 22.4 & 67.3 & 15.6 \\
$\begin{array}{c}\text { Doped spiro- } \\
\text { OMeTAD } \\
\begin{array}{c}\text { Undoped spiro- } \\
\text { OMeTAD }\end{array}\end{array}$ & 1.03 & 22.3 & 65.8 & 15.2 \\
\hline
\end{tabular}

